\title{
Introduction to WeChat Interface Design Localization
}

\author{
Xun Yuan \\ College of Fine Arts \\ Huanggang Normal University \\ Huanggang, China
}

\author{
Chen Qiu \\ College of Fine Arts \\ Huanggang Normal University \\ Huanggang, China
}

\begin{abstract}
With the development of The Times, people use social software not only for their purpose and convenience, but also to pay more attention to the visual experience. WeChat is a social software that has been developing rapidly in the past two years, and its visual design directly affects user's satisfaction. Combining the modern design with the local style, the Chinese charm can be reflected and promoted as well as another inheritance of traditional culture.
\end{abstract}

Keywords—local culture; visual language; interface design

\section{INTRODUCTION}

In this era of new media's rise, the Internet has become more and more widely used. WeChat has become an essential means of communication for people. Nowadays, people lay more emphasize on individuation, and visual design will directly affect the user's satisfaction. Since the reform and opening, we have been learning the western design concept and style, but seldom think about the design and development of our nation. China is a country with profound cultural deposits which need inherit and develop the traditional culture. Modern design comes from the west, but we can't be bound by western culture. And the combination of native style and modern design of national character can meet the innovation spirit of modern society. Meanwhile, combining traditional Chinese culture with western modern design, a new culture can be formed to realize the goal of internationalization from localization.

\section{LOCAL VISUAL LANGUAGE IMPLEMENTING INTERFACE DESIGN STYLIZATION}

\section{A. Localized Visual Language}

Localization, on the one hand, refers to the national culture of local, individual or traditional characteristics, on the other hand, means to integrate the foreign culture with their own reality, and transform into their own things. The localization design is more inclined to the latter, absorbing the western design concept and style, and combining with the traditional Chinese cultural characteristics, to get out of a road of Chinese characteristics design. Visual language is a language form of visual communication, which constructs the visual language through the graphs, images, colors and other factors. From The Visual Language written by David Cohen and Scott Anderson, it is known that there are a line, shape, color, color, texture, form, scale, space, light, etc to constitute the basic elements of visual language. The characteristics of visual language have simplicity, vividness, temporal and national character. ${ }^{1}$ The simplicity of the design is concise, easy to read and recognize; vividness refers to moving people and making them more receptive; Contemporaneity refers to innovating constantly as time progresses; nationality, formed in the long history of a nation, which embodies the different styles and beliefs of the nation, is also an important aspect of this study. And combine localization with visual language to form a design of Chinese flavor, which can not only extend the culture of a nation itself, but also derive new design concepts to interpret the meaning of innovation.

\section{B. The Stylization of the Interface Design of Visual Language}

The interface design needs to follow the prominent principle, the whole principle and the personalized design principle. Personalized design principle, the interface design not only provides convenient and fast operation for users, but also can combine other cultures to innovate design, to bring visual freshness to the users. Visual language is indispensable in interface design, and the interface design needs to be stylized through visual language packaging, which is also necessary to follow the principle of personalized design. The presenting of visual language influences users' first impression and the interface design of text, graphic, color elements belong to visual language. To realize the interface design style is to the basic elements of the visual language style, is the basic elements of the visual language for the creative innovation design.

\section{THE DIFFERENCE BETWEEN THE INTERFACE DESIGNS OF WECHAT AND THE SIMILAR SOFTWARE}

\section{A. Analysis of WeChat Interface}

WeChat interface is mainly in the minimalist style of green, full of clarity and integrality, and the same function using the same graphics greatly reduces the users' memory burden. WeChat's icon design is also very simple and easy to identify, which provides convenience for users in operation. But because of the influence of western design, the WeChat interface has been in the imitation stage, leading to the loss of the localization feature of other foreign software in function and appearance.

\footnotetext{
${ }^{1}$ David Cohen, Scott Anderson, Xu Li, Visual Language [M], Shanghai People's Art Press, 2012
} 


\section{B. WeChat Interface Compared with FaceBook's and Tencent's $Q Q$ Interface}

FaceBook is a social tool for connecting with friends abroad. And its function is very similar to WeChat, which is indispensable in people's life. The main tone of FaceBook is dark blue, and the original intention of the designer is to avoid inconvenience of colorblind people using, full of humanization. Designers think more simplicity is more easy to recognize, and more convenient to operate. So FaceBook uses a minimalist interface, which is very similar to WeChat. The main hue of WeChat is green, except that the green color is used in other basic tones of black grey and white. It is also very simple in color, which is very popular nowadays.

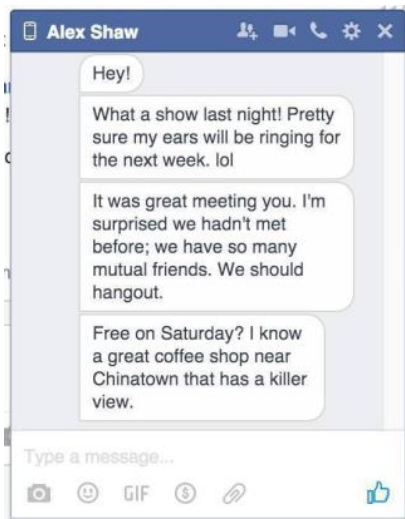

Fig. 1. Chat interface of FaceBook (source: network).

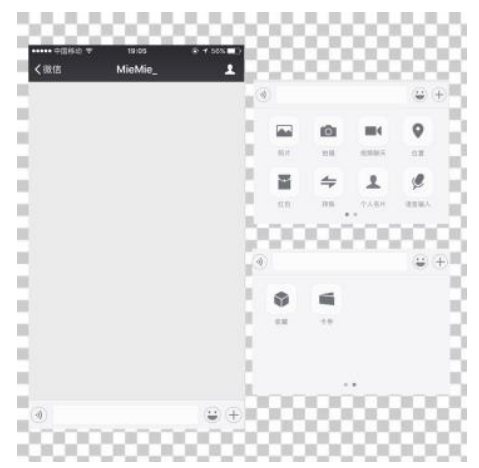

Fig. 2. Chat interface of WeChat (source: network).

I picked the chat screenshots for comparison between two, as shown in figures, "Fig. 1" is a chat interface of FaceBook, each message has its own borders, to highlight the number of messages. The name of the other party is in the upper left corner, and there are other icons at the top right corner such as addition of friends, video chat, voice call, setting and exit. Below the interface are the input field, camera, emoticons, dynamic figure, transfer, labels to exist for convenience. "Fig. $2 "$ is WeChat's interface, the other party name located in the middle of the above, the upper left corner is quit the icon, the upper right corner of the icon is to search each other information, below the chat voice input, keyboard input, expressions and a plus sign icon. Unlike FaceBook, WeChat leaves only the input bar and chat emojis, hiding other features in the addition icon, which looks more minimalist. And FaceBook has a thumb up icon more than WeChat, and you can quickly click on the thumb up icon when you agree with what the other person is saying.

The interface design of WeChat is very similar to that of FaceBook. Both of them are mainly in simple styles, which capture the social needs of users, make the real life more Networking and interpersonal communication more convenient. But the minimalist style after all comes from the west, I think WeChat also should add a bit of their own traditional culture while drawing on western design style, so as not to have been in a state of learning. It is in need of this innovative spirit that the national cultural characteristics can be integrated with the modern society and developed.

QQ is a popular communication software in China, with the same amount of users as WeChat. QQ and WeChat are both owned by Tencent, but the users' experience is very different. The following analysis is made from both login interfaces: "Fig. 3" is the login screen of tencent's QQ. It is a penguin made of colored pieces, which means a colorful and easily lost youth. "Fig. 4" is the WeChat's login screen. It is a lonely man standing in front of the huge earth at night, showing the vastness of the universe and the eternal loneliness of mankind. The moral is that when loneliness comes, WeChat will meet you in the world. Both interfaces can show a certain connotation, some deep meaning, and the same expression forms roughly.

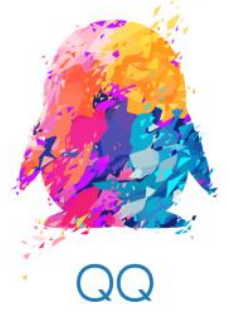

Fig. 3. The login interface of tencent QQ (source: network).

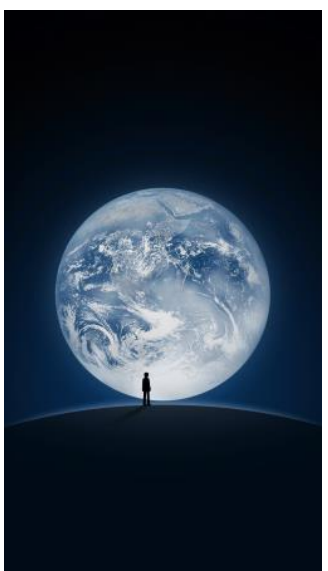

Fig. 4. The login interface of WeChat (source: network). 
The basic login interfaces of tencent QQ and WeChat are roughly the same. However, every time it meets the festival, QQ's login interface will add an interface related to the festival. Even every time it meets a festival or an important day, tencent QQ will launch a related login interface and a related theme. As shown in "Fig. 5": Children's day is a concern in details; in "Fig. 6", the college entrance exam is calm. Different from WeChat, QQ captures the user's psychology, that during the festival, many people's emotions and ideas tend to be very close, and the design is more likely to resonate. WeChat remains constant, lack of a cultural transmission.
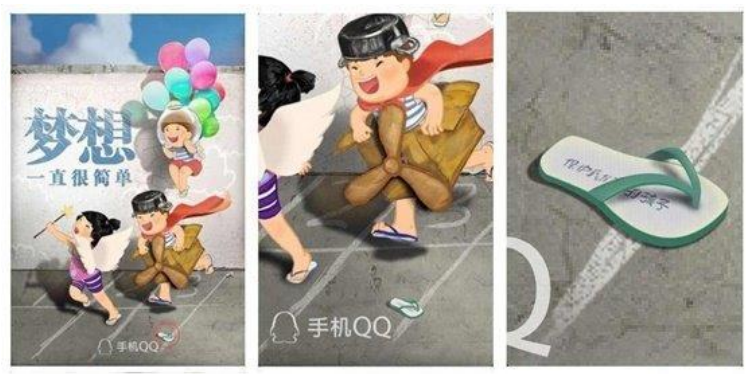

Fig. 5. Care of children's day in QQ interfaces (source: network).
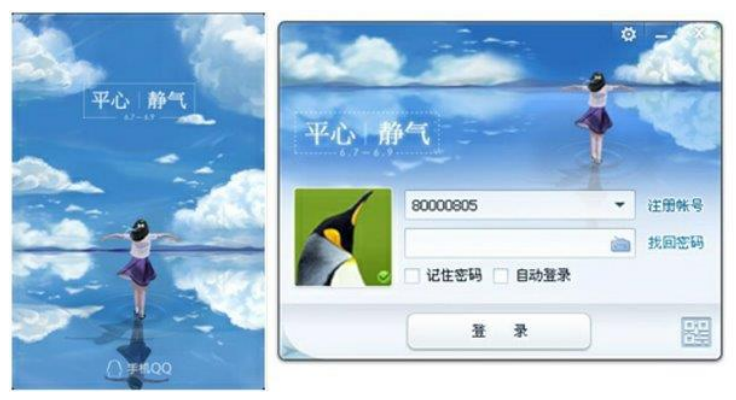

Fig. 6. Display the calm of the college entrance exam in QQ interfaces (source: network).

\section{Draw A Conclusion by Comparison}

By the comparison between the interfaces of WeChat, FaceBook and tencent QQ, we found that WeChat interface design has been influenced by western, imitated western style, without its own unique culture. Only combining western design culture learned and the native culture, keeping to innovate, finally having a chance to put other things into our own, then develop and inherit own culture to be more internationalization.

\section{THE EXPRESSION OF THE LOCALIZATION DESIGN OF WECHAT INTERFACE}

The four steps of visual design are defined, separated, transformed, and aggregated. In particular, it is necessary to analyze the problem to determine the target audience, and then to conduct regionalization research, visualize the image, and finally spliced it together. Designer Stephen Schdeming had hoped to say, "Create a design touching people's hearts." ${ }^{2}$ For this purpose, he began to explore the history and content of

${ }^{2}$ Ian Noble, Russell Best, Liu Xiaolin (translated) Visual Design Method [M]. Liao Ning: Liao Ning Science and Technology Press, 2010. cultural use. If the visual design is integrated into traditional national culture, it will have a certain resonance with people, which also makes the modernization gradually accept the tradition. It is important to take full advantage of various elements, excavate the symbolic and representative of the elements, and be able to take the initiative to carry out the spread and development of culture. ${ }^{3}$

\section{A. The Localized Text Element}

The localization of text elements should be emphasized in font design. With the development of the Times, the design of Chinese characters faces the changing of media and communication technology. If Chinese traditional culture is to be embodied in the text, the traditional art form of characters can be integrated into modern design, which is to create a new type of traditional font. Chinese character art has gradually moved away from the rich cultural accumulation, and has not found a suitable track to integrate into modern society. ${ }^{4}$ The combination of Chinese character culture and interface design can create a new development track.

For example, WeChat has a single limited font type for interface design. In order to reflect the simplicity, there is no font style to choose, only the size can be adjusted. If we add a personalization to font settings, design a few more traditional fonts. For example, the integration of ancient traditional patterns with modern fonts, and font designs representing Chinese characteristics can be involved as shown in "Fig. 7". This may lead to more interesting fonts for users to choose. And users also can feel the profound traditional Chinese culture of characters while experiencing personalized fonts. Of course, there are users who don't like it. And it doesn't conflict that because personalized settings of the initiative is the users themselves, use or not only depends on the users' own ideas, but increasing the font of personalized settings also provides users with more choices. "Fig. 8" shows that the Chinese character Shu body replaces WeChat's original Microsoft Ya black font, making the picture more traditional.

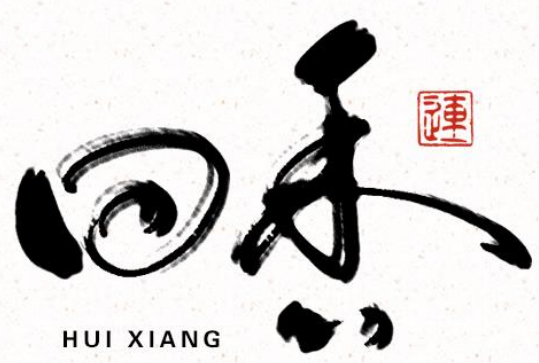

Fig. 7. Combination of ancient traditional patterns and modern fonts (source: network).

\footnotetext{
${ }^{3}$ Chen Xinhua. Elements and Originality [M]. Jiangsu: Jiang Su Fine Arts Press, 2008.

${ }^{4}$ Ji Tie, Zhou Xu. Font Design [M]. Beijing: People's Fine Arts Press, 2008.
} 


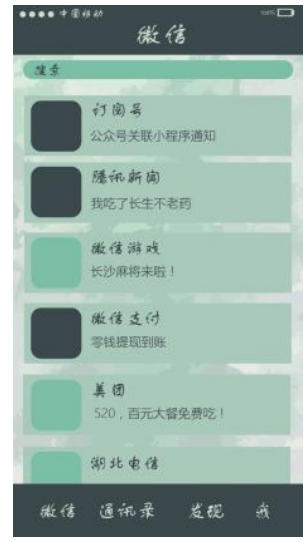

Fig. 8. Chinese character Shu body replaces the WeChat interface (designer: Qiu Chen).

\section{B. The Localized Graphical Elements}

The biggest feature of graphic elements is vivid and intuitive, which is a kind of visual information. Comparing to text elements, graphic elements are more expressive and more widely designed. Traditional Chinese culture has been long since ancient times. In ancient times, there were fish patterns, bird and animal lines, fruit and flower patterns and weaving patterns. This is a texture with distinctive national characteristics. We can integrate the patterns developed and evolved from traditional Chinese culture with modern elements, and apply it to WeChat interface. Open WeChat indicator icon is essential elements to guide users. If we put these icons stylized, substitute traditional things reflected by Chinese style, we can have certain resonance with the user directly from the vision. Not only design on the icon, but also we can carry out the association on the entry screen.

In every Chinese traditional festival, we can get WeChat into the theme of the interface. However, on the basis of thematic change, the original design concept is not changed, which is to preserve the essential elements of the earth, boys and so on, and to create on these elements. For example: at the time of the Mid-Autumn festival, the users open the WeChat and see into the frame, have resonated with it subconsciously, perhaps the next step would have opened chat screen with their parents. Isn't this a way to incorporate holiday traditions into your life? As shown in "Fig. 9" is the WeChat interface design of Dragon Boat Festival, I combine the Dragon Boat Festival dragon boat culture with the interface of WeChat itself, using the basic elements of the dragon boat and Zong $\mathrm{Zi}$ to carry on the design. "Fig. 10" is a WeChat entry interface designed by me, using the elements of Mid-Autumn festival, which gives users a more festival visual experience.

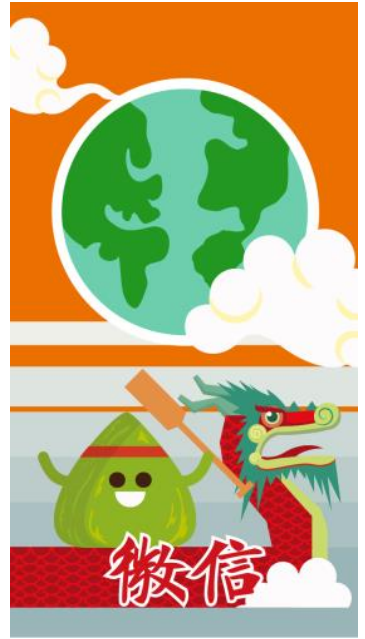

Fig. 9. WeChat entry interface design of Dragon Boat Festival (designer: Qiu Chen).

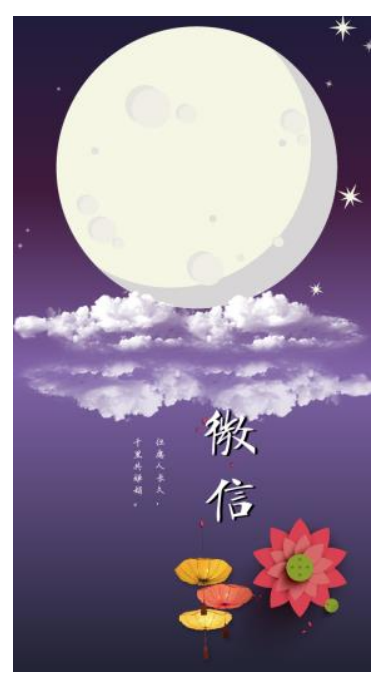

Fig. 10. WeChat entry interface designed by the elements of Mid-Autumn festival (designer: Qiu Chen)

\section{Color Style Reflecting Localization}

The color culture of China is the beauty of tradition. The concept of color includes philosophy, ethics, nature and universe, which can be said to be profound. ${ }^{5}$ The traditional beauty of color is an indispensable part of localization design. In the case of a single red, the names of coral red, carmine, bright red, pomegranate red, and different colors can be combined to reflect ethnic characteristics as shown in "Fig. 11". We can use a single color to collide to form a color with Chinese wind, and apply it to WeChat interface, so that the interface style is no longer a single green and full of more Chinese color. In addition to designing some traditional colors that can reflect the Chinese style, users can also bring out their own colors to make WeChat more personalized. Fig.12 shows the WeChat main interface that I designed with the traditional Chinese icon, and uses many icons with Chinese characteristics to indicate icons. Colors are using the low

\footnotetext{
${ }^{5}$ Hong Yang. Traditional Colors [M]. Oriental Press, 2010.
} 
purity of red and green, which are also the Chinese unique color styles, with the combination of local color can make the interface design more traditional.

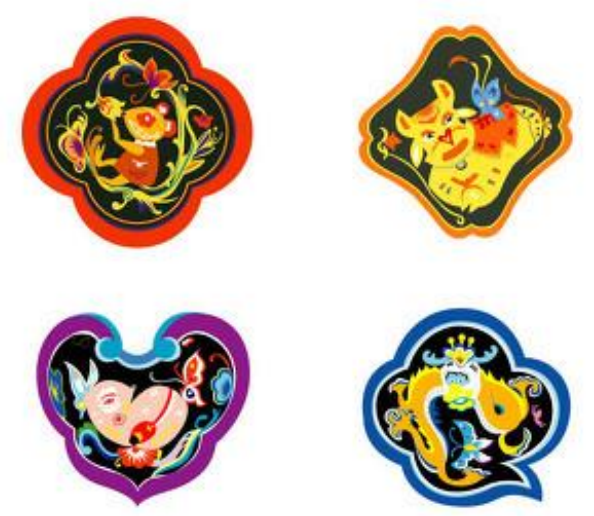

Fig. 11. National characteristics of different color combinations (source: network)

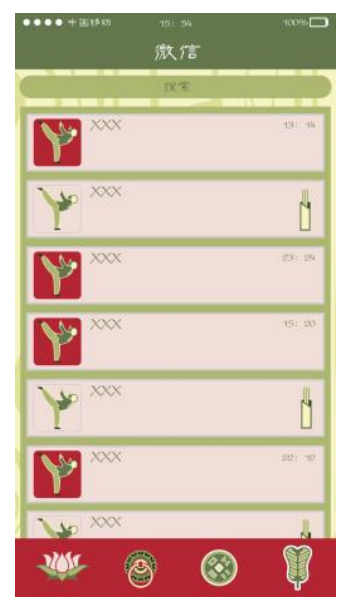

Fig. 12. The combination of localization color makes interface design traditional (designer: Qiu Chen).

\section{The Characteristics of Texture Reflecting Localization}

First of all, texture is the expression of the surface texture characteristics. The application of artistic texture in interface design can not only enhance its visual sense, but also make people interested. There are many traditional textures in China, such as relief, embroidery, marble and jade, etc. We can apply these effects to WeChat interface design to make the vision more interesting. For example, different textures can be combined with colors to use in the background of WeChat interface and other personalized settings. This is also the creative transformation of traditional culture, the embodiment of the texture effect makes the art form richer, and also makes the traditional culture more vivid in the eyes of the people. I design the texture effect of Chinese ink in "Fig. 13" and the background of the micro interface in "Fig. 14".

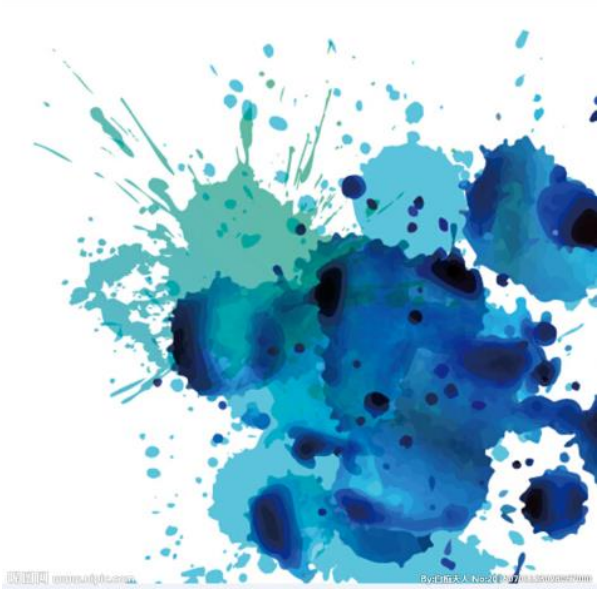

Fig. 13. Texture effect of Chinese ink (source: network).

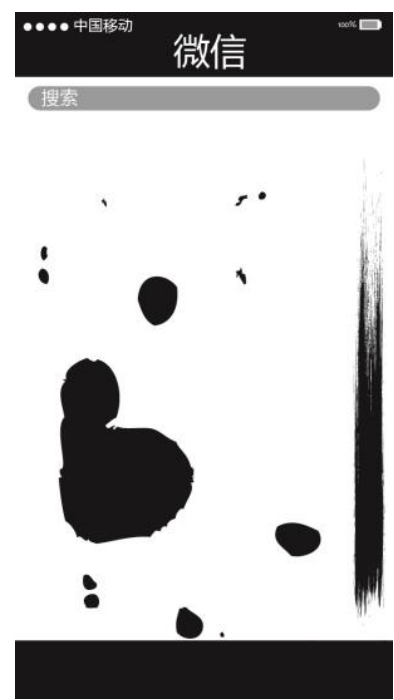

Fig. 14. The texture effect of Chinese ink and combined with micro interface background (designer: Qiu Chen).

In general, we want to incorporate the traditional culture into the WeChat interface design depending on the word "innovation". The modernization of traditional culture is to update the traditional culture, make it meet the demands of modernization, and also can use new medium of the Internet to develop WeChat traditional culture so as not to easily forgotten.

\section{CONCLUSION}

Modern design is more and more approbation of the localed design style, which is the design of Chinese traditional culture. However, Chinese culture is not a closed system, which has diversity and integrates with other cultures to create a new culture, which is also the pursuit of modern design. We are often influenced by western culture and neglect the cultural beauty of our own nation. Combining localization design with modern design is not only to enable traditional culture to develop and inherit, but also to bring traditional culture to a larger stage, which is an international stage.

In this era of rapid development of new media, we can not only pursue the latest trend of fashion but forget the long 
history of our culture. The modernization of culture and art is inevitable in history, but we can't take the liberty of imitating the western modernist. We should use the innate advantage of Chinese traditional culture to create a new design with more Chinese color and national flavor. WeChat localization of the interface design is a new try, a new start, only combining the experience of others and their own not to be assimilated. It only tries to innovate to have the chance to discover new vitality towards internationalization.

\section{REFERENCES}

[1] David Cohen, Scott Anderson, Xu Li (translat). Visual language [M]. Shanghai: People's Fine Arts Press, 2012.

[2] Ian Noble, Russell Best, Liu Xiaolin (translat) Visual Design Method [M]. Liao Ning: Liao Ning Science and Technology Press, 2010.

[3] Chen Xinhua. Elements and Originality [M]. Jiangsu: Jiang Su Fine Arts Press, 2008.

[4] Ji Tie, Zhou Xu. Font Design [M]. Beijing: People's Fine Arts Press, 2008.

[5] Hong Yang. Traditional Colors [M]. Oriental Press, 2010.

[6] Li Rongqi. A Multi-Perspective Exploration of Culture and Art [M]. Bei Jing: Beijing Times Chinese Press, 2015.

[7] Qian Mu. From the Perspective of Chinese History, Chinese Nationality and Chinese Culture Can Be Seen [M]. Zhong Hua Book , 2016.

[8] Li Yaqi. Brief Discussion on "Localization" Design Thought [J]. Mass Literature, 2016.

[9] Sun Jun. A Discussion on the Inheritance and Development of Traditional Culture in the Localized Design Language [J]. Beauty and the Time, 12 periods of 2009.

[10] Ju Dehui. The Localization and Globalization of Design Languages [J]. Art And Design, 2009. 